\title{
Load Balancing Per Connection Classifier dengan Pengukuran Quality of Service pada Jaringan LAN Lingkup Universitas
}

\author{
Aulia Desy Nur Utomo ${ }^{\# 1}$, Puji Sarwono *2 \\ Prodi Teknik Informatika, Institut Teknologi Telkom Purwokerto \\ Jl. D.I. Panjaitan. No. 128, Purwokerto 53147, Banyumas, Jawa Tengah, Indonesia \\ 1 auliautomo@ittelkom-pwt.ac.id \\ Program Studi Magister Informatika, Universitas Islam Indonesia \\ Jalan Kaliurang KM 14.5, Sleman, Daerah Istimewa Yogyakarta 55584 \\ ${ }^{2} 16917114 @$ students.uii.ac.id
}

Accepted on 19-05-2020

\begin{abstract}
Abstrak
Dalam penggunaan jaringan internet yang bersifat umum atau digunakan secara bersama perlu menerapkan konfigurasi jaringan yang sesuai untuk memaksimalkan penggunaan koneksi internet yang disediakan oleh provider. Hal ini penting untuk penggunaan layanan internet yang lebih optimal dan sesuai dengan utilitasnya yaitu penggunaan traffic bandwidth secara bersama dapat tercapai secara seimbang. Per Connection Classifier adalah metode penyeimbangan beban atau Load Balancing untuk mendistribusikan beban traffic ke lebih dari satu titik koneksi jaringan secara seimbang, sehingga lalu lintas traffic jaringan dapat berjalan secara optimal.

Penelitian ini berfokus pada metode konfigurasi jaringan untuk memaksimalkan penggunaan bandwidth internet untuk semua user. Quality of Service digunakan untuk melihat kinerja traffic jaringan yang ditunjukkan oleh nilai parameter delay, throughput, dan packet loss.

Berdasarkan hasil pengujian dan penelitian yang telah dilakukan sebelum dan sesudah menggunakan load balancing per koneksi clasifier, nilai delay terjadi penurunan dari 180,26 ms menjadi 148,36 ms dan throughput meningkat dari 1,76\% menjadi 2,03\%, kemudian packet loss menurun dari 25,37\% menjadi 18,59\% sesuai dengan standarisasi TIPHON.
\end{abstract}

Kata Kunci : Quality of Service, Per Connection Classification, Load Balancing, Delay, Throughput, Packet Loss

\section{PENDAHULUAN}

$\mathrm{D}$ alam perkembangan dunia telekomunikasi sangat berpengaruh terhadap komunikasi dan interaksi di dalam masyarakat, baik organisasi, institusi serta lembaga pendidikan. Salah satu perkembangan teknologi telekomunikasi adalah layanan komunikasi data, atau pelayanan internet. Seiring dengan perkembangannya, layanan internet sangat dibutuhkan karena penyampaian informasinya yang cepat dan efisien.

Dalam lingkungan institusi, kantor serta lembaga pendidikan penggunaan layanan internet pada jam kerja hampir secara serentak digunakan secara bersamaan, baik mengakses aplikasi online yang digunakan kantor ataupun media informasi email, web, chatting, browsing, video multimedia, perkuliahan daring dan sebagainya, 
ini akan mengakibatkan layanan internet yang tersedia akan terbebani dan saling berebut antar user dengan user yang lain untuk memenuhi kebutuhan akses datanya.

Universitas sebagai institusi pendidikan yang memiliki integritas tinggi untuk memajukan civitas akademikanya, harus memiliki banyak kelengkapan fasilitas pendukung sarana dan prasarana pendidikan, baik dari segi operasional maupun laboratorium khususnya laboratorium komputer. Tetapi dalam pelaksanaannya penggunaan layanan dalam hal ini internet pada jam kerja dalam satu waktu secara bersamaan akan mempengaruhi kinerja operasional pendidikan serta kegiatan belajar mengajar. Hal ini ditandai dengan penggunaan layanan internet pada laboratorium komputer dan perkuliahan daring pada server yang tidak stabil, seringnya terjadi 'not connection' atau putus nyambung, lamanya proses unggah dan entri data pada sistem informasi dan e-learning universitas yang menjadi permasalahan utama pada setiap kampus dan institusi pendidikan.

Melihat permasalahan tersebut untuk kelancaran operasional pendidikan perlu diterapkannya konfigurasi jaringan yang optimal untuk kebutuhan dari setiap user. Pada konfigurasi internet diterapkan metode Load Balancing Per Connection Classifier, dimana penggunaan metode ini diharapkan dapat melancarkan pendistribusian beban traffic pada dua atau lebih jalur koneksi secara seimbang agar traffic dapat berjalan optimal dan terorganisir, dan juga dapat memaksimalkan throughput, memperkecil waktu tanggap atau delay untuk memaksimalkan Quality of Service dari masing-masing user, serta dapat menghindari overload pada salah satu jalur koneksi pada jaringan.

\section{TINJAUAN PUSTAKA}

Dalam penelitian ini, digunakan beberapa referensi sumber pustaka yang berasal dari jurnal dan penelitian yang sudah dilakukan oleh [1] dalam penelitian yang berjudul "Implementasi Load Balancing Menggunakan Metode Per Connection Classifier Dengan Failover Berbasis Mikrotik Router” (Studi Kasus PT. Sumber Rejeki Power), yang bertujuan untuk memberikan optimasi penggunaan bandwidth jaringan komputer yang menitik beratkan pada user agar setiap koneksi user terbagi secara seimbang.

Penelitian lainnya tentang load balancing pernah dilakukan oleh [2] dengan judul "Keseimbangan Bandwidth Dengan Menggunakan Dua ISP Melalui Metode Nth Load Balancing Berbasiskan Mikrotik". Penelitian ini bertujuan untuk menyeimbangkan dua koneksi provider dari dua ISP yang berbeda.

Rujukan penelitian yang berhubungan dengan konfigurasi jaringan komputer berikutnya dilakukan oleh [3] dengan judul "Perancangan Pengelolahan Jaringan Load Balancing dan Fileover Menggunakan Router Mikrotik Rb 951 Series Pada Stkip Pgri Lubuklinggau". Penelitian ini bertujuan untuk membuat rancangan pengelolaan jaringan menggunakan metode Load Balancing.

Penelitian lain dilakukan oleh [4] dengan judul "Simulasi Implementasi Load Balancing Per Connection Classifier Menggunakan Simulator Gns3”. Penelitian ini menitik beratkan pada implementasi load balancing pada jaringan sehingga beban trafick yang diperoleh jadi lebih lancer tanpa ada penumpukan data.

Berdasarkan referensi penelitian diatas, penulis melakukan penelitian pada Fakultas Bisnis dan Teknologi Universitas Teknologi Yogyakarta (F-ITB), dimana terdapat perbedaan infrastruktur, tata letak ruangan dan gedung, institusi dan tata kelola jaringan sehingga berpengaruh pada Quality of Service dari pelayanan internet kepada seluruh user.

\section{METODE PENELITIAN}

\section{A. Analisis Masalah}

Penerapan load balancing per connection classifier akan diimplementasikan secara langsung pada jaringan internet di F-ITB, penerapan konfigurasi ini digunakan untuk melakukan pengujian dan dianalisis kinerjanya melalui hasil pengukuran pada tiap tahapan implementasi dengan tiga parameter Quality of Servive yaitu delay, throughput dan packet loss. 


\section{B. Analisis Kebutuhan Sistem}

Analisis kebutuhan sistem bertujuan untuk membahas bagaimana implementasi load balancing per connection clasifier dapat menyelesaikan masalah pada jaringan F-ITB dan mengidentifikasi kebutuhan perangkat lunak dan perangkat keras yang digunakan.

\section{1) Analisis Kebutuhan Perangkat Keras}

Terdapat beberapa macam perangkat keras yang digunakan termasuk diantarany perangkat Komputer yang digunakan sebagai komputer client pada laboratorium komputer dan ruang kantor operasional pendidikan, yangdalam penelitian ini sebagai measurement point atau node dilakukannya pengambilan data dan pengukuran.Routerboard Mikrotik digunakan untuk tempat pengkonfigurasian per connection classifier. .Laptop yang digunakan sebagai salah satu node dan juga perekap keseluruhan data dan pengukuran

\section{2) Analisis Kebutuhan Perangkat Lunak}

Terdapat beberapa macam perangkat lunak yang digunakan termasuk diantarany Aplikasi wireshark Networking yang akan digunakan pada masing-masing komputer client untuk mendapatkan nilai data pengukuran untuk menentukan nilai delay dan troughput. Aplikasi Axence Net Tools digunakan juga digunakan pada masing-masing komputer client untuk mendapatkan nilai data pengukuran untuk menentukan nilai packet loss. Aplikasi Ping digunakan untuk mengirimkan paket ICMP pada masing-masing komputer client untuk mengetes konektifitas antar komputer.

\section{Perancangan Pengujian}

Berdasarkan hasil pengamatan infrastruktur dan keluhan user tentang koneksi internet yang lambat,. pengujian akan dilakukan pada setiap laboratorium komputer Fakultas Bisnis dan Teknologi UTY dan pada ruang operasional kantor. Berikut adalah lokasi measurement point pengujian yang ditunjukkan pada Gambar 1. Pada Gambar1 adalah lokasi tempat pengukuran.dan penempatan konfigurasi pada router.

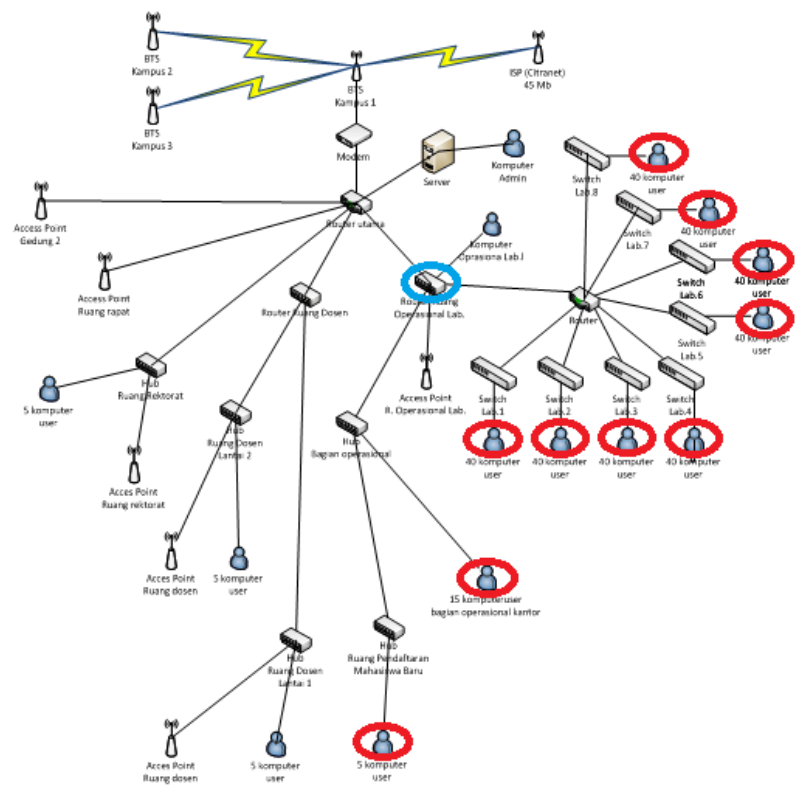

Gambar 1. Lokasi Pengukuran dan Penempatan konfigurasi router

Pengujian dilakukan pada 8 laboratorium komputer dan ruang operasional kantor. Setiap laboratorium terdapat 40 komputer dan 10 komputer pada ruang operasional kantor, sehingga terdapat 330 komputer user sebagai measurement point pengukuran dan pengujian untuk mendapatkan sampel data trafik internet guna menentukan nilai delay, throughput dan packet loss. Konfigurasi per connection clasifier diterapkan pada router operasional laboratorium Pengujian dilakukan pada jam kerja dan dilakukan secara bersamaan dalam satu waktu 
untuk dapat melihat kinerja bandwith dalam jaringan. Pengujian melibatkan mahasiswa, dosen dan karyawan untuk membantu mengumpulkan data dari seluruh komputer measurement point

\section{Perancangan Skenario Pengukuran}

Dari hasil pengamatan data trafik perancangan pengujian, sekenario pengukuran dilakukan selama tiga minggu di dalam bulan Oktober dimulai pada tanggal 3 Oktober 2018 sampai tanggal 23 Oktober 2018 dengan ketentuan dalam satu minggu dilakukan tiga kali pengukuran yaitu pada hari Senin, Rabu, Jumat dan setiap minggunya pada hari yang sama, keadaan yang sama kegaiatan yang sama. Dari sini akan dapat terlihat peningkatan kinerja bandwidth karena diukur pada kondisi yang sama

Pengukuran dilakukan dengan konfigurasi yang berbeda, pengukuran pada minggu pertama adalah pengukuran dengan konfigurasi jaringan yang ditetapkan F-ITB, pada minggu kedua pengukuran dengan menerapkan Per Connection Classifier, pada router utama yang menuju laboratorium komputer dan operasional kantor.

Sekenerio pengukuran yang diterapkan adalah, pada waktu antara pukul 07.00 - 12.00 WIB yaitu setiap satu jam dari jam 07.00 WIB sampai dengan 12.00 WIB akan diambil sampel pengukuran dari parameter delay, throughput dan packet loss selama 3 kali, durasi pengambilan data yaitu 1 menit, jadi setiap satu jam akan diambil rata-rata data trafic yang didapat. Kemudian dijumlahkan satu jam selanjutnya sampai pukul 12.00 WIB.

\section{E. Persiapan perangkat pengujian dan pengukuran yang digunakan}

Persiapan perangkat yang digunakan berguna untuk mempersiapkan perangkat keras dan perangkat lunak pengukuran layanan jaringan yang akan di pasang dan diterapkan pada jaringan internet F-ITB.

\section{1) Perangkat keras}

Proses pengukuran layanan jaringan internet dilakukan dengan mempersiapkan perangkat keras yang dibutuhkan yaitu setiap komputer user operasional kantor dan laboratorium komputerserta router mikrotik. Pada Gambar 2 menunjukkan komputer desktop yang digunakan oleh setiap user.

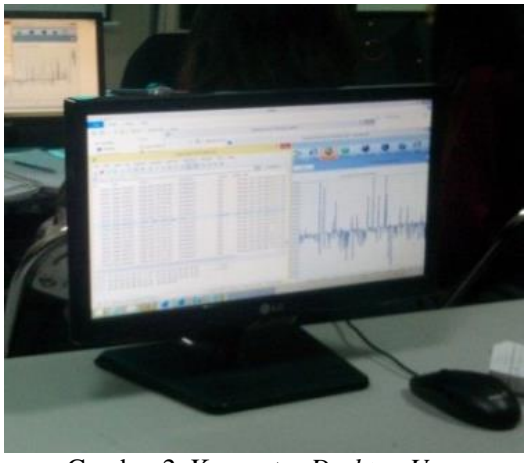

Gambar 2. Komputer Desktop User

Menggunakan satu buah laptop sebagai salah satu user dan untuk rekap data pengukuran. Pada Gambar 3 menunjukkan laptop yang digunakan. 


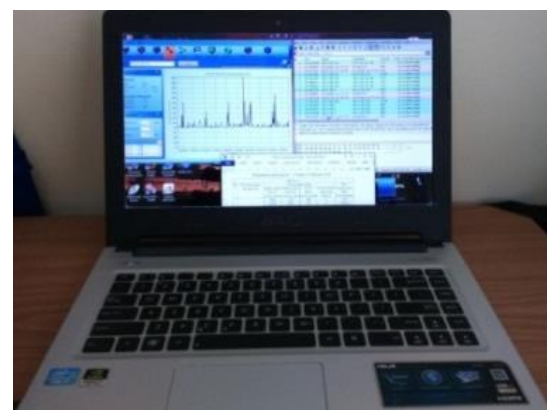

Gambar 3. Laptop Asus A46CM-WX095D

Menggunakan satu buah routerboard. Pada Gambar 4 menunjukkan router yang digunakan.

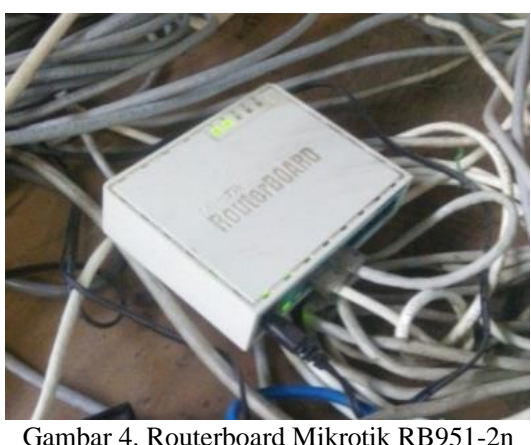

\section{2) Perangkat Lunak}

Perangkat lunak yang digunakan dalam penelitian ini adalah Apilkasi Wareshark, AplikasiAxence Net Tools, Aplikasi Ping pada Windows.

\section{HASIL DAN PEMBAHASAN}

\section{A. Implementasi load balancing Per Connection Classifier pada router Mikrotik}

Pada pengaturan load balancing Per Connection Classifier dikelompokan trafic koneksi yang melalui atau keluar masuk router menjadi beberapa kelompok trafic. Pengelompokan ini dibedakan berdasarkan srcaddress, dst-address, src-port dan atau dst-port. Sehingga router akan mencatat jalur gateway yang dilewati pada awal trafic koneksi, kemudian pada paket-paket selanjutnya yang masih berkaitan dengan koneksi atau paket awal akan dilewatkan pada jalur gateway yang ditetapkan.

Pembuatan pengaturan manglein-interface pada traffic load balance client diatas adalah interface yang terhubung dengan client, dan untuk traffic load balance web proxy, penulis menggunakan chain output dengan parameter out-interface yang bukan terhubung ke interface client[5]. Setelah custom chain untuk load balancing dibuat, kemudian membuat mangle pada custom chain tersebut dengan mengetikkan perintah sebagai berikut. Berikut ini adalah script mangle untuk pengaturan load balancing pada in-interface dan out-interface.

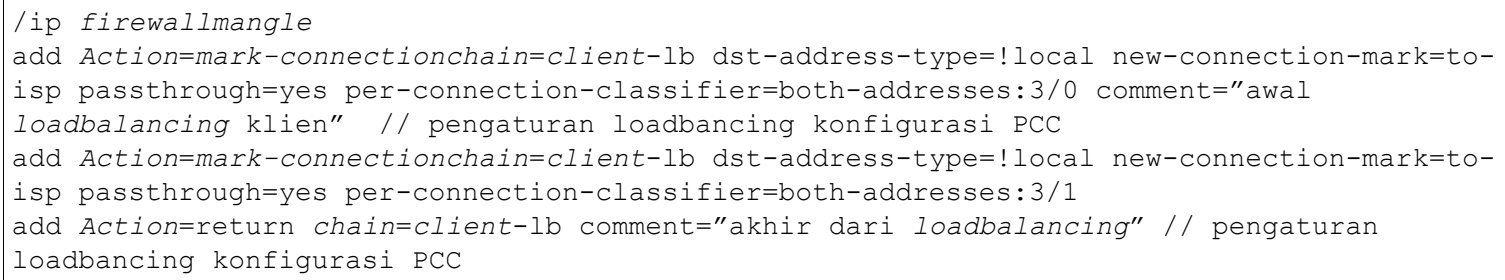


lip firewallmangle

add Action=mark-connectionchain=lb-proxy dst-address-type=!local new-connection-mark=con-

from-isp passthrough=yes per-connection-classifier=both-addresses:3/0 comment="awal load

balancing proxy" // pengaturan load balancing proxy

add Action=mark-connectionchain=lb-proxy dst-address-type=!local new-connection-mark=con-

from-isp passthrough=yes per-connection-classifier=both-addresses:3/1

add Action=return chain=lb-proxy comment="akhir dari loadbalancing" // pengaturan load

balancing proxy

Script mangle untuk pengaturan loadbalancing pada in-Interface dan out-Interface

Pada load balancing client dan web proxy menggunakan parameter pemisahan trafic PCC yang sama, yaitu both-address, sehingga router akan mencatat berdasarkan src-address dan dst-address dari sebuah koneksi [6]. Jika masing-masing trafic dari client dan proxy sudah ditandai, kemudian membuat manglemarkroute yang akan digunakan dalam proses routing. Pengaturan ini diterapkan dengan mengetikkan perintah sebagai berikut [7]. Berikut ini adalah script mangle mark-route untuk proses routing.

lip route

add check-gateway=ping dst-address=0.0.0.0/0 gateway=192.168.11.1 routing-mark=route-to-isp distance=1 // konfigurasi mangle mark-route

Script mangle mark-route untuk proses routing

Dari hasil inputan keseluruhan script metode PCC dihasilkan konfigurasi pada mikrotik sebagai berikut. Pada Gambar 7 adalah hasil input konfigurasi PCC pada routerboard Mikrotik.

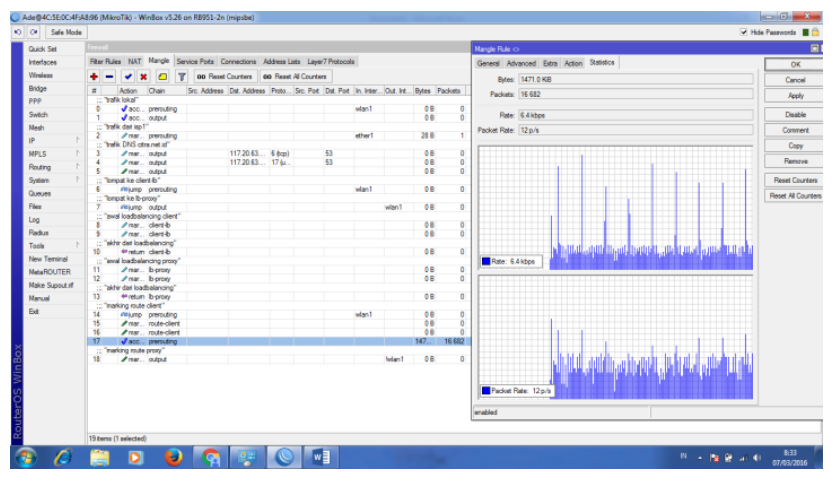

Gambar 5. Hasil input konfigurasi PCC

\section{B. Implementasi pengukuran}

Pengukuran dilakukan menggunakan bantuan aplikasi wareshark dan Axen Net Tools, untuk mendapatkan data nilai pengukuran yang valid.

\section{1) Pengukuran delay}

Parameter delay dilakukan dengan pengukuran aktif menggunakan aplikasi ping dan Wireshark, untuk mendapatkan nilai data untuk menentukan delay, implementasi pengukuran dilakukan dari sisi keseluruhan user laboratorium komputer dan operasional kantor menuju sitedestination address google.com (216.58.196.46) dengan data sebesar 32 bytes. Pengukuran delay memerlukan protokol ping sebagai sample ICMP yang mengirim data kepada side address tujuan. Perintah ping dilakukan dengan mengetikkan perintah ping ip address. Sebagai contoh, “ping google.com” pada windows bar command prompt 


\section{2) Pengukuran Throughput}

Penentuan nilai throughput dilakukan dengan pengukuran aktif yang dibantu dengan menggunakan aplikasi Wireshark. Implementasi pengukuran dilakukan dari sisi keseluruhan user laboratorium komputer dan operasional kantor.

\section{3) Pengukuran Packet Loss}

Pengukuran packet loss dilakukan menggunakan pengukuran aktif dengan mengirimkan data sebesar 32 bit yang diukur pada sisi WAN side dengan side address:www.google.com (101.203.171.79). pengukuran packet losss menggunakan aplikasi Axence net Tolls.

C. Pengujian trafic Minggu pertama sebelum menggunakan Load Balance Per Connection Classifier Parameter yang diuji delay, throughput,packet loss.

1) Pengukuran Delay

Tabel untuk hasil pengukuran delay minggu pertama ditunjukkan pada Tabel 1

TABEL 1

RATA - RATA DELAY HARIAN SETIAP LAB. KOMPUTER DAN R. KANTOR.

\begin{tabular}{|c|c|c|c|c|c|c|c|c|c|c|c|c|}
\hline Hari Pengukuran & \multicolumn{9}{|c|}{ Data Pengukuran Rata-rata delay } & Rara - rata & Indeks & Keterangan \\
\hline \multirow[t]{2}{*}{ Minggu ke-1 } & \multicolumn{9}{|c|}{ per-laboratorium komputer dan R. Kantor } & delay per hari & peringkat & kualitas \\
\hline & Lab.1 & Lab.2 & Lab.3 & Lab. 4 & Lab.5 & Lab.6 & Lab.7 & Lab. 8 & R. Kantor & & & \\
\hline Senin, 3 Oktober 2018 & 156,07 & 173,18 & 169,05 & 176,95 & 190,07 & 183,13 & 169,74 & 189,09 & 173,85 & 175,68 & 3 & Bagus \\
\hline Rabu, 5 Oktober 2018 & 171,51 & 186,64 & 156,02 & 180,59 & 191,37 & 185,36 & 179,76 & 178,18 & 165,33 & 177,20 & 3 & Bagus \\
\hline Jumat, 7 Oktober 2018 & 184,92 & 174,83 & 176,88 & 183,38 & 199,34 & 191,95 & 198,95 & 197,25 & 183,70 & 187,91 & 3 & Bagus \\
\hline \multicolumn{13}{|c|}{ Rata-rata delay Minggu ke-1 pada tiga hari kerja dari pukul $07.00 \mathrm{~s} / \mathrm{d} 12.00 \mathrm{WIB}$} \\
\hline Delay Minggu ke-1 & 170,83 & 178,22 & 167,32 & 180,31 & 193,59 & 186,81 & 182,82 & 188,17 & 174,29 & 180,26 & 3 & Bagus \\
\hline
\end{tabular}

Grafik untuk hasil pengukuran delay minggu pertama ditunjukkan pada Gambar 6.

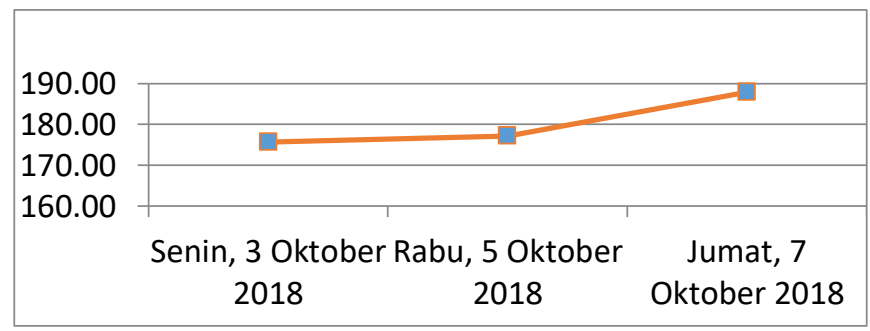

Gambar 6. Grafik rata - rata delay harian

2) Pengukuran Throughput

Tabel untuk hasil pengukuran throughput minggu pertama ditunjukkan pada Tabel 2 
TABEL 2

RATA-RATA THROUGHPUT HARIAN SETIAP LAB. KOMPUTER DAN R. KANTOR.

\begin{tabular}{|c|c|c|c|c|c|c|c|c|c|c|c|c|}
\hline Hari Pengukuran & \multicolumn{9}{|c|}{ Data Pengukuran Rata-rata throughput (\%) } & Rara - rata & Indeks & Keterangan \\
\hline \multirow[t]{2}{*}{ Minggu ke-1 } & \multicolumn{9}{|c|}{ per-laboratorium komputer dan R. Kantor } & & peringkat & kualitas \\
\hline & Lab.1 & Lab.2 & Lab.3 & Lab. 4 & Lab.5 & Lab.6 & Lab.7 & Lab.8 & R. Kantor & $(\%)$ & & \\
\hline Senin, 3 Oktober 2018 & 1,64 & 1,70 & 1,89 & 1,72 & 1,88 & 1,81 & 1,79 & 1,78 & 1,68 & 1,77 & 1 & Masih dapat ditoleri \\
\hline Rabu, 5 Oktober 2018 & 1,71 & 1,68 & 1,76 & 1,78 & 1,80 & 1,75 & 1,73 & 1,81 & 1,74 & 1,75 & 1 & Masih dapat ditoleri \\
\hline Jumat, 7 Oktober 2018 & 1,69 & 1,78 & 1,88 & 1,72 & 1,75 & 1,80 & 1,70 & 1,85 & 1,82 & 1,78 & 1 & Masih dapat ditoleri \\
\hline \multicolumn{13}{|c|}{ Rata-rata throughput Minggu ke-1 pada tiga hari kerja dari pukul $07.00 \mathrm{~s} / \mathrm{d} 12.00 \mathrm{WIB}$} \\
\hline Delay Minggu ke-1 & 1,68 & 1,72 & 1,84 & 1,74 & 1,81 & 1,79 & 1,74 & 1,81 & 1,75 & 1,76 & 1 & Masih dapat ditolerii \\
\hline
\end{tabular}

Grafik untuk hasil pengukuran throughput minggu pertama ditunjukkan pada Gambar 7.

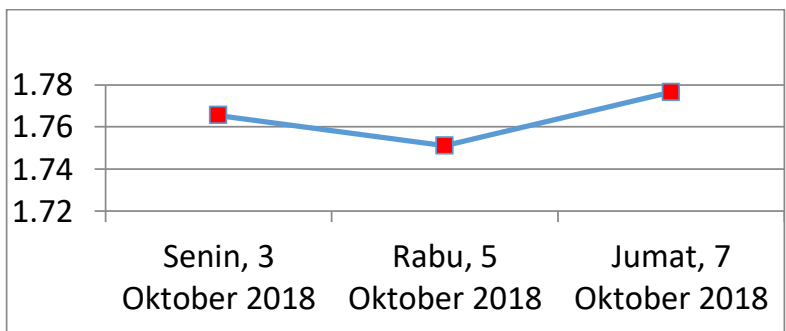

Gambar 7. Grafik rata - rata persentase throughput harian

3) Pengukuran Packet loss

Tabel untuk hasil pengukuran packet loss minggu pertama ditunjukkan pada Tabel 3

TABEL 3

RATA - RATA PACKET LOSS HARIAN SETIAP LAB. KOMPUTER DAN R. KANTOR

\begin{tabular}{|c|c|c|c|c|c|c|c|c|c|c|c|c|}
\hline Hari Pengukuran & \multicolumn{9}{|c|}{ Data Pengukuran Rata-rata packet loss (\%) } & Rara - rata & Indeks & Keterangan \\
\hline \multirow[t]{2}{*}{ Minggu ke-1 } & \multicolumn{9}{|c|}{ per-laboratorium komputer dan R. Kantor } & packet loss & peringkat & kualitas \\
\hline & Lab.1 & Lab.2 & Lab.3 & Lab. 4 & Lab.5 & Lab.6 & Lab.7 & Lab.8 & R. Kantor & $(\%)$ & & \\
\hline Senin, 3 Oktober 2018 & 27 & 25 & 27 & 26 & 24 & 25 & 23 & 24 & 26 & 25,22 & 1 & Jelek \\
\hline Rabu, 5 Oktober 2018 & 26 & 24 & 25 & 24 & 26 & 28 & 27 & 25 & 24 & 25,44 & 1 & Jelek \\
\hline Jumat, 7 Oktober 2018 & 25 & 23 & 26 & 28 & 23 & 27 & 26 & 25 & 27 & 25,56 & 1 & Jelek \\
\hline \multicolumn{13}{|c|}{ Rata-rata throughput Minggu ke-1 pada tiga hari kerja dari pukul 07.00 s/d 12.00 WIB } \\
\hline Delay Minggu ke-1 & 26,00 & 24,00 & 26,00 & 26,00 & 24,33 & 26,67 & 25,33 & 24,67 & 25,67 & 25,41 & 1 & Jelek \\
\hline
\end{tabular}

Grafik untuk hasil pengukuran packet loss minggu pertama ditunjukkan pada Gambar 8 .

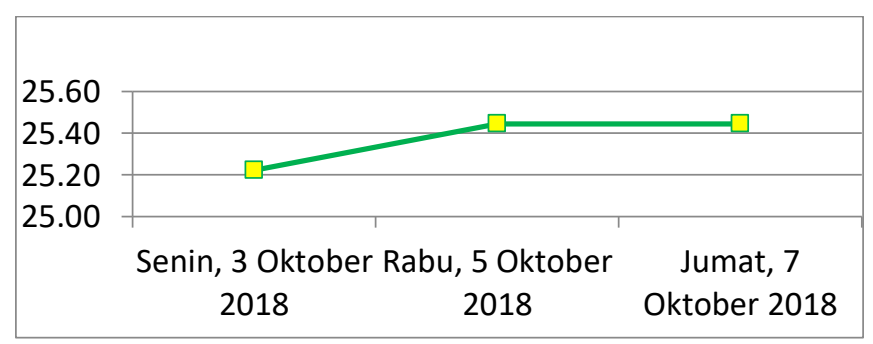

Gambar 8. Grafik rata-rata packet loss harian 
D. Pengujian trafic Minggu kedua dengan menggunakan metode Load Balance Per Connection Classifier. Pengujian delay, throughput dan packet loss

1) Pengukuran Delay

Tabel untuk hasil pengukuran delay minggu kedua ditunjukkan pada Tabel 4

TABEL 4

RATA - RATA DELAY HARIAN SETIAP LAB. KOMPUTER DAN R. KANTOR.

\begin{tabular}{|c|c|c|c|c|c|c|c|c|c|c|c|c|}
\hline Hari Pengukuran & \multicolumn{9}{|c|}{ Data Pengukuran Rata-rata delay } & Rara - rata & Indeks & Keterangan \\
\hline \multirow[t]{2}{*}{ Minggu ke-2 } & \multicolumn{9}{|c|}{ per-laboratorium komputer dan R. Kantor } & delay per hari & peringkat & kualitas \\
\hline & Lab.1 & Lab.2 & Lab.3 & Lab. 4 & Lab.5 & Lab.6 & Lab.7 & Lab.8 & R. Kantor & & & \\
\hline Senin, 10 Oktober 2018 & 141,14 & 130,33 & 156,56 & 159,82 & 172,18 & 155,96 & 152,02 & 169,50 & 137,26 & 152,75 & 3 & Bagus \\
\hline Rabu, 12 Oktober 2018 & 143,19 & 131,51 & 153,79 & 139,75 & 166,26 & 145,67 & 150,84 & 149,66 & 132,09 & 145,86 & 4 & Sangat Bagus \\
\hline Jumat, 14 Oktober 2018 & 140,40 & 141,27 & 146,15 & 134,25 & 156,08 & 165,42 & 149,54 & 155,91 & 129,28 & 146,48 & 4 & Sangat Bagus \\
\hline \multicolumn{13}{|c|}{ Rata-rata delay Minggu ke-2 pada tiga hari kerja dari pukul 07.00 s/d 12.00 WIB } \\
\hline Delay Minggu ke-2 & 141,58 & 134,37 & 152,17 & 144,61 & 164,84 & 155,68 & 150,80 & 158,36 & 132,88 & 148,36 & 4 & Sangat Bagus \\
\hline
\end{tabular}

Grafik untuk hasil pengukuran delay minggu kedua ditunjukkan pada Gambar 9.

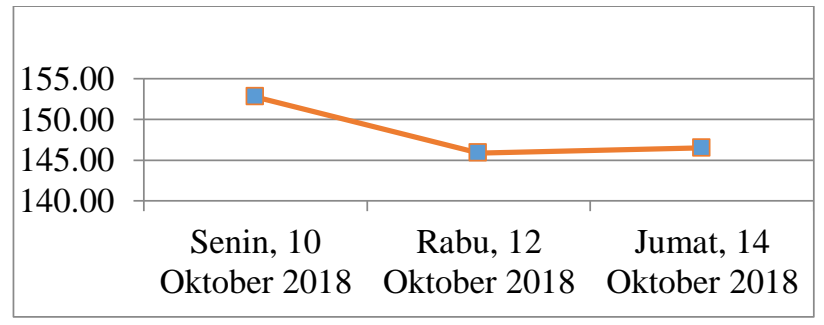

Gambar 9. Grafik rata-rata delay harian

\section{2) Pengukuran Throughput}

Tabel untuk hasil pengukuran throughput minggu kedua ditunjukkan pada Tabel 5

TABEL 5

RATA-RATA THROUGHPUT HARIAN SETIAP LAB. KOMPUTER DAN R. KANTOR.

\begin{tabular}{|c|c|c|c|c|c|c|c|c|c|c|c|c|}
\hline Hari Pengukuran & \multicolumn{8}{|c|}{ Data Pengukuran Rata-rata throughput (\%) } & $\begin{array}{c}\text { Rara - rata } \\
\text { throughput } \\
\text { Minggu ke-2 }\end{array}$ & \multicolumn{1}{|c|}{$\begin{array}{c}\text { Indeks } \\
\text { per hari }\end{array}$} & Keterangan \\
& peringkat & kualitas \\
& Lab.1 & Lab.2 & Lab.3 & Lab. 4 & Lab.5 & Lab.6 & Lab.7 & Lab.8 & R. Kantor & $(\%)$ & & \\
\hline Senin, 10 Oktober 2018 & 1,86 & 2,08 & 1,96 & 2,01 & 2,07 & 2,05 & 1,91 & 1,96 & 2,09 & 2,00 & 1 & Masih dapat ditolerir \\
\hline Rabu, 12 Oktober 2018 & 2,03 & 1,98 & 2,13 & 2,10 & 2,14 & 1,96 & 2,04 & 2,14 & 1,98 & 2,06 & 1 & Masih dapat ditolerir \\
\hline Jumat, 14 Oktober 2018 & 2,06 & 1.90 & 2,01 & 2,12 & 1,92 & 2,15 & 2,13 & 1,97 & 2,02 & 2,05 & 1 & Masih dapat ditolerir \\
\hline \multicolumn{10}{|c|}{ Rata-rata throughput Minggu ke-2 pada tiga hari kerja dari pukul 07.00 s/d 12.00 WIB } \\
\hline Delay Minguu ke-2 & 1,98 & 2,03 & 2,03 & 2,08 & 2,04 & 2,05 & 2,03 & 2,02 & 2,03 & 2,03 & 1 & Masih dapat ditolerir \\
\hline
\end{tabular}

Grafik hasil pengukuran througuhput minggu pertama ditunjukkan pada Gambar 10. 


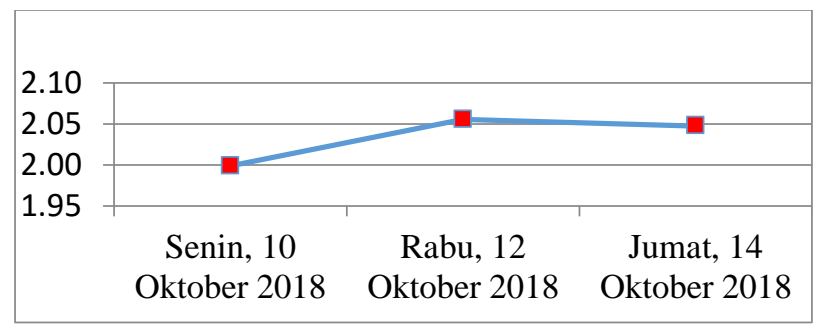

Gambar 10. Grafik persentase rata-rata throughput harian

\section{3) Pengukuran Packet loss}

Tabel untuk hasil pengukuran packet loss minggu kedua ditunjukkan pada Tabel 6

TABEL 6

RATA - RATA PACKET LOSS HARIAN SETIAP LAB. KOMPUTER DAN R.KANTOR

\begin{tabular}{|c|c|c|c|c|c|c|c|c|c|c|c|c|}
\hline Hari Pengukuran & \multicolumn{9}{|c|}{ Data Pengukuran Rata-rata packet loss (\%) } & Rara - rata & Indeks & Keterangan \\
\hline \multirow[t]{2}{*}{ Minggu ke-2 } & \multicolumn{9}{|c|}{ per-laboratorium komputer dan R. Kantor } & packet loss & peringkat & kualitas \\
\hline & Lab.1 & Lab.2 & $\mathrm{Lab} .3$ & $\mathrm{Lab} .4$ & Lab.5 & Lab.6 & Lab.7 & Lab.8 & R. Kantor & $(\%)$ & & \\
\hline Senin, 10 Oktober 2018 & 20 & 19 & 20 & 19 & 18 & 18 & 20 & 19 & 18 & 19,00 & 2 & Sedang \\
\hline Rabu, 12 Oktober 2018 & 19 & 20 & 19 & 17 & 18 & 17 & 18 & 19 & 19 & 18,44 & 2 & Sedang \\
\hline Jumat, 14 Oktober 2018 & 18 & 20 & 18 & 19 & 17 & 17 & 18 & 17 & 21 & 18,33 & 2 & Sedang \\
\hline \multicolumn{13}{|c|}{ Rata-rata throughput Minggu ke-2 pada tiga hari kerja dari pukul $07.00 \mathrm{~s} / \mathrm{d} 12.00 \mathrm{WIB}$} \\
\hline Delay Minggu ke-2 & 19,00 & 19,67 & 19,00 & 18,33 & 17,67 & 17,33 & 18,67 & 18,33 & 19,33 & 18,59 & 2 & Sedang \\
\hline
\end{tabular}

Gafik untuk hasil pengukuran packet loss minggu kedua ditunjukkan pada Gambar 11.

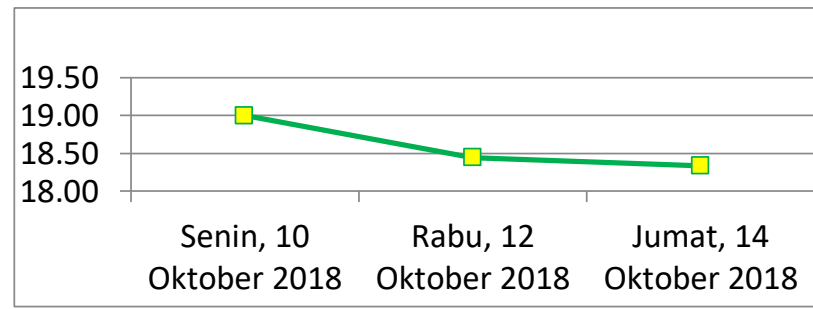

Gambar 11. Grafik rata-rata packet loss harian

\section{E. Analisa hasil pengujian}

Tabel untuk hasil perbandingan hasil pengukuran ditunjukkan pada Tabel 10

TABEL 10

PERBANDingan RATA-RATA HASIL PENGUKURAN

\begin{tabular}{|c|l|c|c|c|}
\hline \multirow{2}{*}{ No. } & \multicolumn{4}{|c|}{ Sebelum Penerapan Metode Load Balance Per Connection Clasifier } \\
\cline { 2 - 5 } & \multicolumn{1}{|c|}{ Parameter } & Nilai & Indeks & Keterangan \\
\hline 1 & QoS & Rata-rata & Nilai & Kualitas \\
\hline 2 & Throughput $(\%)$ & 1.76 & 3 & Bagus \\
\hline 3 & Packet Loss $(\%)$ & 25.37 & 1 & Masih dapat ditolerir \\
\hline & \multicolumn{5}{|c|}{ Setelah Penerapan Load Balance Per Connection Clasifier } \\
\hline 1 & Delay $(\mathrm{ms})$ & 148.36 & 4 & Sangat Bagus \\
\hline 2 & Throughput $(\%)$ & 2.03 & 1 & Masih dapat ditolerir \\
\hline 3 & Packet Loss $(\%)$ & 18.59 & 2 & Sedang \\
\hline
\end{tabular}

Pada Gambar 11. adalah grafik perbandingan hasil pengukuran delay 


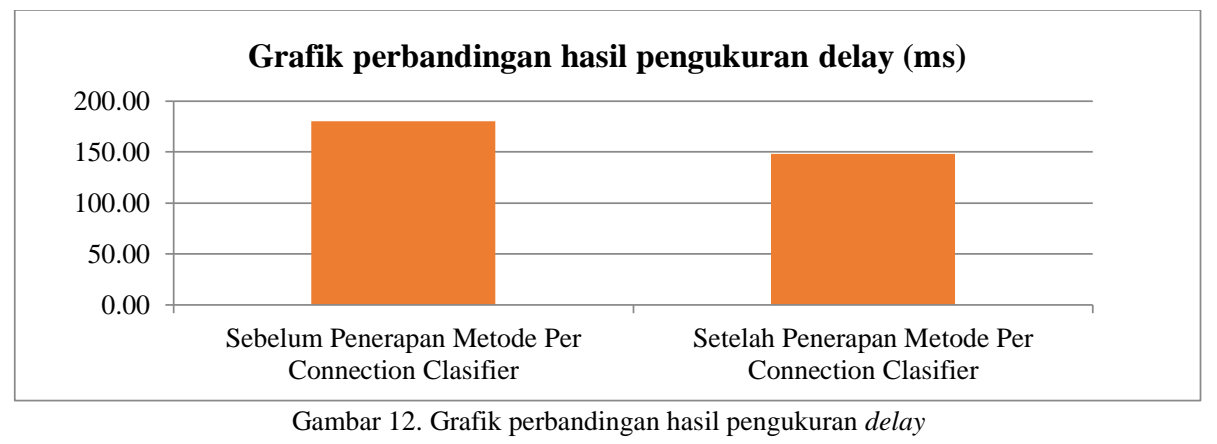

Pada Gambar 13 adalah grafik perbandingan hasil pengukuran throughput

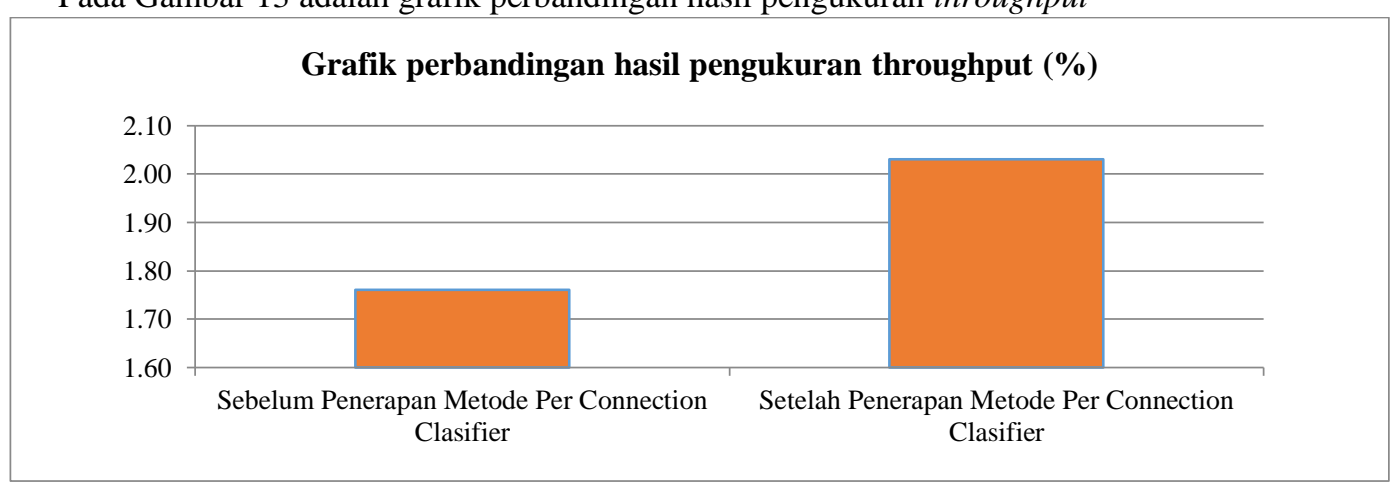

Gambar 13. Grafik perbandingan hasil pengukuran throughput

Pada Gambar 14 adalah grafik perbandingan hasil pengukuran packet loss

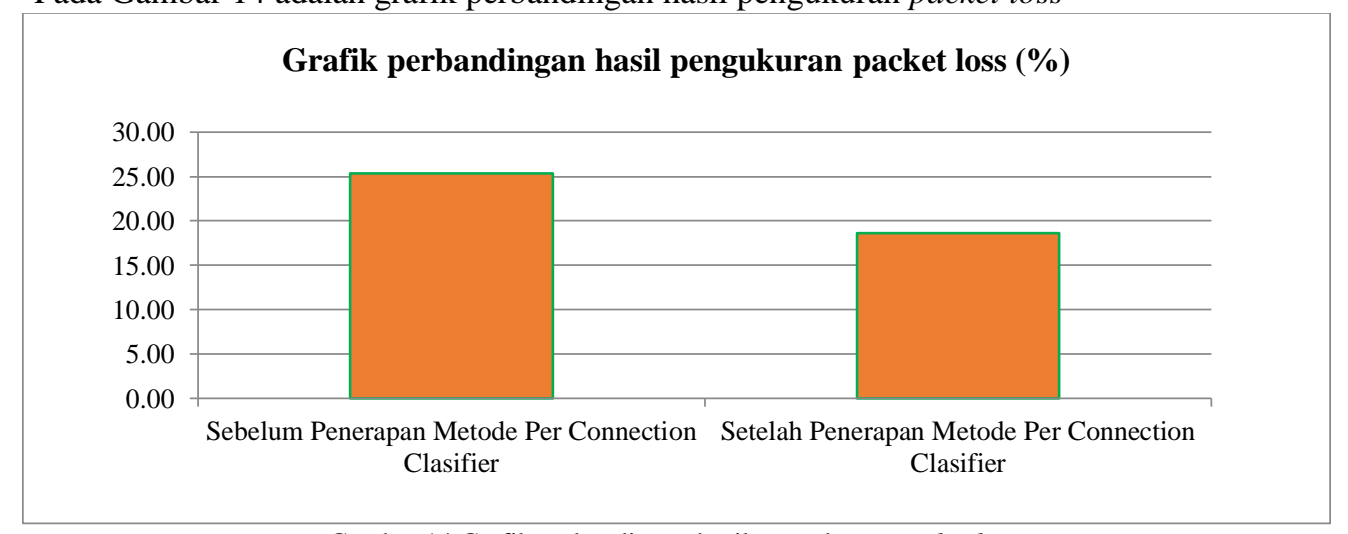

Gambar 14 Grafik perbandingan hasil pengukuran packet loss.

\section{KESIMPULAN}

Berdasarkan pengujian dan pengukuran yang telah dilakukan, maka dapat diambil kesimpulan sebagai berikut :

1. Telah dilakukan pengujian penerapan Load Balancing Per Connection Clasifier pada jaringan F-ITB. Dibuktikan dengan hasil pengukuran setiap parameter QoS delay, throughput dan packet loss menggunakan standar TIPHON yang memperlihatkan perbedaan nilai signifikan dari sebelum diterapkannya konfigurasi dan setelah diterapkannya konfigurasi 
2. Hasil yang didapatkan untuk nilai delay mengalami penurunan dari $180,26 \mathrm{~ms}$ menjadi $148,36 \mathrm{~ms}$ dan untuk throughput mengalami kenaikan dari 1,76 \% menjadi 2,03\%, kemudian untuk packet loss mengalami penurunan dari $25,37 \%$ menjadi $18,59 \%$.

Saran yang dapat dikembangkan dalam penelitian lebih lanjut sebagai berikut:

1. Untuk penelitian lebih lanjut, diharapkan sampel pengukuran dalam waktu satu hari, atau pada delapan jam kerja. Agar dapat dilihat keseluruhan trafik selama satu hari kerja.

2. Pada penelitian lebih lanjut diharapkan menggunakan lebih banyak parameter QoS yang digunakan, agar data yang didapat lebih optimal. 


\section{UCAPAN TERIMAKASIH}

Syukur Alhamdulillah saya panjatkan kehadirat Allah SWT atas segala limpahan Rahmat dan KaruniaNya sampai saat ini masih diberikan kesehatan dan semangat yang luar biasa sehingga dapat menyelesaikan penulisan jurnal, dengan berjudul "Load Balance Per Connection Classifier dengan Quality of Service pada jaringan LAN Lingkup Universitas”.

Penulis menyadari bahwa tanpa bantuan dan dukungan dari berbagai pihak penyusunan jurnal dan penelitian ini tidak dapat berjalan dengan baik. Sehubungan dengan hal tersebut, maka pada kesempatan ini, perkenankanlah penulis menyampaikan terima kasih yang sebesar-besarnya kepada:

1 Didi Supriyadi, S.T., M.Kom., ITIL Selaku Dekan Fakultas Informatika Institut Teknologi Telkom Purwokerto.

2 Fahrudin Mukti Wibowo, S.Kom., M.Eng. Selaku Ketua Program Studi Teknik Informatika, Fakultas Informatika Institut Teknologi Telkom Purwokerto.

3 Muhammad Fajar Sidiq, S.T., M.T. Selaku Sekertaris Program Studi Teknik Informatika, Fakultas Informatika Institut Teknologi Telkom Purwokerto.

4 Orang tua dan istri saya Rosana Amalia yang selalu memberikan semangat dan mendoakan dalam menyelesaikan jurnal penelitian ini.

5 Teman-teman di Program Studi Informatika yang telah banyak membantu dan memberikan sharing pengetahuan dan dukungan dalam jenjang karir

Akhir kata semoga Allah SWT memberikan balasan yang sepadan dengan kebaikan-kebaikan yang telah diberikan dan semoga karya ini dapat bermanfaat bagi semua pihak serta memberikan sumbangan kepada Ilmu Pengetahuan dan Teknologi khususnya di bidang Informatikan, Amin Yaa Robbal Alamin. 


\section{DAFTAR PUSTAKA}

[1] Suryanto, T. Prasetyo, dan N. Hikmah, 2018. Implementasi Load Balancing Menggunakan Metode Per Connection Classifier dengan Failover Berbasis Mikrotik Router (Studi Kasus PT. Sumber Rejeki Power). Seminar Nasional Inovasi dan Tren (SNIT).

[2] T. Sukendar, 2017. . Keseimbangan Bandwidth Dengan Menggunakan Dua ISP Melalui Metode Nth LoadBalancing Berbasiskan Mikrotik. Jurnal Teknik Komputer Amik Bsi. III (1). hal. 86.

[3] Armanto, 2017. Perancangan Pengelolahan Jaringan Load Balancing dan Fileover Menggunakan Router Mikrotik Rb 951 Series Pada Stkip Pgri Lubuklinggau. JUSIKOM. 2 (2). hal. 83.

[4] A. M. Elhanafi, I. Lubis, dan D. Irwan, 2018. Simulasi Implementasi Load Balancing Per Connection Classifier Menggunakan Simulator Gns3. JutiKomp. 